\title{
BMJ Open Time trends in access to smoking cessation support for people with depression or severe mental illness: a cohort study in English primary care
}

\author{
Milena Falcaro, ${ }^{1}$ David Osborn, ${ }^{2}$ Joseph Hayes, ${ }^{2}$ Lisa Couperthwaite, ${ }^{3}$ \\ Scott Weich, ${ }^{4}$ Kate R Walters (1) ${ }^{5}$
}

To cite: Falcaro M, Osborn D, Hayes $\mathrm{J}$, et al. Time trends in access to smoking cessation support for people with depression or severe mental illness: a cohort study in English primary care. BMJ Open 2021;11:e048341. doi:10.1136/ bmjopen-2020-048341

Received 22 December 2020 Accepted 05 November 2021

Check for updates

(C) Author(s) (or their employer(s)) 2021. Re-use permitted under CC BY. Published by BMJ.

For numbered affiliations see end of article.

Correspondence to Professor Kate R Walters; k.walters@ucl.ac.uk

\section{ABSTRACT}

Objectives To investigate delivery of smoking cessation interventions, recorded quit attempts and successful quitting rates within primary care in smokers with depression or severe mental illness (SMI) compared with those without.

Design Longitudinal cohort study using primary healthcare records.

Setting English primary care.

Participants 882849 patients registered with participating practices recorded as current smokers during 2007-2014, including three groups: (1) 13078 with SMI,

(2) 55630 with no SMI but recent depression and (3) 814 141 with no SMI nor recent depression.

Outcomes Recorded advice to quit smoking, referrals to smoking cessation services, prescriptions for smoking cessation medication, recorded quit attempts and changes of smoking status.

Results The majority (>70\%) of smokers had recorded smoking cessation advice. This was consistently higher in those with SMI than the other cohorts of patients, although the gap greatly reduced in more recent years. Increases in smoking cessation advice over time were not accompanied by increases in recorded attempts to quit or changes of smoking status. Overall nicotine replacement therapy prescribing by general practitioners (GPs) was higher in those with SMl $(10.1 \%)$ and depression (8.7\%) than those without (5.9\%), but a downward time trend was observed in all groups. Bupropion and varenicline prescribing was very low and lower for those with SMI. Few smokers $(<5 \%)$ had referrals to stop smoking services, though this increased over time, but no significant differences were observed between those with and without mental health problems.

Conclusions There was no evidence of consistent inequalities in access to GP-delivered smoking cessation interventions for people with mental health conditions. Smoking cessation advice was widely reported as taking place in all groups. In order to address the widening gap in smoking prevalence in those with poor mental health compared with those without, the emphasis should be on addressing the quality of advice and support given.

\section{INTRODUCTION}

Poor mental health has been shown to be the most common single cause of
Strengths and limitations of this study

$\Rightarrow$ This is, to our knowledge, the first nationally representative study evaluating trends over time in smoking cessation management practices in people with depression and severe mental illness compared with the general population in English primary care.

$\Rightarrow$ Our data set includes robust information on smoking cessation prescriptions in primary care in England.

$\Rightarrow$ The data set is however limited only to prescribed medications and does not include over-the-counter nicotine replacement therapy or e-cigarette use.

$\Rightarrow$ There is likely to be under-recording of smoking quit attempts and smoking status changes in primary care records.

disability-adjusted life years lost globally. ${ }^{1}$ Studies have found that people with mental ill-health have elevated mortality rates ${ }^{23}$ and that for those with severe mental illness (SMI; schizophrenia, bipolar disorder and other non-organic psychoses) this mortality gap has been widening over the last decade in the UK. ${ }^{4}$ Smoking is often seen as a means of coping with stress and is more common in those with poor mental health. ${ }^{5-7}$ Prevalence rates of smoking were $34.1 \%$ in those with common mental disorders compared with $19.6 \%$ in those without mental health conditions in $2014,{ }^{8}$ and higher rates are seen in those with SMI $(58 \%$ in men and $41 \%$ in women in the UK). ${ }^{7}$ However, it is a key modifiable risk factor which greatly contributes to the excess risk of cardiovascular diseases (CVD) and mortality observed in this population. It is therefore an important target for intervention. There is consistent evidence that quitting smoking leads to improvements in both mental and physical health. ${ }^{9-11}$ It has also been shown that those with mental illness can successfully quit smoking with tailored support. ${ }^{8}$ Effectiveness can be similar 
to the general population, ${ }^{12} 13$ with stronger effects seen in those with current depression in studies with a pharmacological smoking cessation treatment than those with psychological treatments. ${ }^{13}$ However, most of these trials have been conducted in specialist clinic settings in stable populations and findings for longer term outcomes are more mixed, ${ }^{13}$ for example, in the SCIMITAR+ trial improved quit rates at 6 months are not sustained by 12 months in people with SMI. ${ }^{14}$

Since people with mental illnesses are in regular contact with their general practice and this is where more assertive management of CVD risk factors-including smoking cessation-may occur, general practitioners (GPs) can play a key role in incentivising and helping patients to stop smoking. There is however to our knowledge little literature that has tested the effectiveness of interventions for smoking cessation in primary care settings for those with mental health problems, with no trials in those with SMI and only one in depression. ${ }^{12} 13$ It is therefore important to assess the management of smoking cessation for people with poor mental health in this setting, including both smoking cessation advice and evidence-based treatments, and to both carefully document patterns of receipt over time and identify areas for improvements. Previous research exploring this has been limited. A cross-sectional study using English primary care data in a single year (July 2009-June 2010) reported that around one-half of smokers with a mental health diagnosis (including SMI and depression, among others) received smoking cessation advice from their GP in that year compared with around one-third of smokers without a mental health diagnosis. ${ }^{15}$ This suggests that GPs may promote smoking cessation more often in those with mental illness, though the content of this advice is unknown. Smoking prevalence is changing over time, reducing from $29.3 \%$ to $19.6 \%$ in those without a mental health condition and from $44.6 \%$ to $34.1 \%$ in those with a common mental disorder (depression and anxiety disorders) between 1993 and 2014 in Great Britain, ${ }^{8}$ the latter remaining therefore much higher than in the general population. ${ }^{81617}$ Furthermore, the gap in CVDrelated mortality for those with mental illness has also been rising over time, ${ }^{4}$ increasing the need to better understand primary care management of smoking cessation in people with SMI and to inform strategies to promote smoking cessation in people with poor mental health.

In this study we examined whether, at the point of recording or updating smoking status to reflect current smoking (ie, when there was an opportunity for smoking interventions to be implemented), GPs were more or less likely to offer smoking cessation interventions to those with depression or SMI compared with those without these conditions. We also investigated if this has changed over time and explored recorded quit attempts and successful quitting.
METHODS

\section{Study design}

Longitudinal cohort study using healthcare records from English primary care.

\section{Data source}

We used electronic health records from the English GP practices that contributed data to The Health Improvement Network (THIN), a large primary care database in the UK. Only data that met quality assurance standards ${ }^{18}$ were retained for analysis. THIN holds information on for example symptoms, diagnoses, referrals, prescribing, health indicators (eg, smoking status) and sociodemographic status. In particular, smoking status has been increasingly better recorded ${ }^{19}$ and is now routinely collected by many GPs as part of the Quality Outcomes Framework $\left(\mathrm{QOF}^{20}\right.$ a pay-for-performance scheme which financially rewards general practices for achieving specific targets across a range of indicators. Marston et $a l^{21}$ reported that around $84 \%$ of patients have had their smoking status recorded at least once during the first year of registration with a GP practice. THIN contains records on the delivery of smoking cessation advice and on quit attempts, although recorded quit attempts are likely to be incomplete as many will attempt this without seeing their GP. Data on smoking cessation pharmacotherapy are available for drugs prescribed by GPs. The first-line medicines for quitting smoking are nicotine replacement therapy (NRT), bupropion and varenicline. The latter two are solely issued on prescription, so their recording is complete. In contrast, NRT can be bought over the counter and, since information about these purchases is not captured in THIN, our findings will be confined to NRT prescribing within primary care. The lack of data on over-the-counter medication in THIN also means that the use of e-cigarettes is also not recorded as these electronic devices are not available on prescription in the UK.

\section{Study population}

We included all patients aged 18 years or over who were permanently registered for at least 6 months with a participating practice between 1 January 2007 and 30 June 2015 and had their smoking status updated to 'current smoker' at least once between the start of the follow-up and 6 months from the end of it. This was chosen as it indicated both a contemporaneous record of their smoking status and an opportunity for the GP to deliver a smoking cessation intervention to that patient. If a patient had multiple updates during the study period, one of them was selected at random and treated as the index event. We restricted the sample to those with at least 6 months of follow-up time to allow time for the outcomes to be recorded. The beginning of the follow-up was set at the latest of the following: 1 January 2007, the patient's 18th birthday, the patient's date of registration with the practice and 1 year after the date the practice achieved an acceptable level of data quality. ${ }^{18}$ The end of the follow-up was the earliest of 30 June 2015, the patient's transfer out of the practice, 
Table 1 Descriptive statistics for the smokers who entered our study

\begin{tabular}{|c|c|c|c|}
\hline & History of SMI & Depression & No SMI nor depression \\
\hline Number of patients (row \%) & $13078(1.5 \%)$ & $55630(6.3 \%)$ & $814141(92.2 \%)$ \\
\hline \multicolumn{4}{|l|}{ Gender } \\
\hline Male & $7325(56.0 \%)$ & $21439(38.5 \%)$ & $431743(53.0 \%)$ \\
\hline Female & $5753(44.0 \%)$ & $34191(61.5 \%)$ & $382398(47.0 \%)$ \\
\hline \multicolumn{4}{|l|}{ Age at index date } \\
\hline Median & 45.1 & 37.7 & 39.5 \\
\hline IQR & $(35.4-56.1)$ & $(27.2-48.5)$ & $(27.8-53.1)$ \\
\hline \multicolumn{4}{|l|}{ Interventions within 6 months from index date } \\
\hline$\%$ Advised to quit & $80.0 \%$ & $73.1 \%$ & $70.3 \%$ \\
\hline$\%$ With referrals to stop smoking services & $2.5 \%$ & $2.5 \%$ & $2.2 \%$ \\
\hline \multicolumn{4}{|c|}{$\%$ With prescribed antismoking drugs medication: } \\
\hline NRT & $10.1 \%$ & $8.7 \%$ & $5.9 \%$ \\
\hline Bupropion & $0.2 \%$ & $0.4 \%$ & $0.4 \%$ \\
\hline Varenicline & $1.3 \%$ & $2.9 \%$ & $3.4 \%$ \\
\hline \multicolumn{4}{|l|}{$\begin{array}{l}\text { Evidence of attempts to quit within } \\
6 \text { months from index date }\end{array}$} \\
\hline$\%$ With recorded quit attempts & $18.3 \%$ & $18.2 \%$ & $16.3 \%$ \\
\hline$\%$ With smoking status change & $5.7 \%$ & $5.9 \%$ & $6.4 \%$ \\
\hline
\end{tabular}

In case a patient had more than one smoking status update to 'current smoker' during the follow-up, we selected one of them at random and used it as the index event.

NRT, nicotine replacement therapy; SMI, severe mental illness.

the patient's date of death or the last date the practice contributed data to THIN.

\section{Outcomes}

We considered outcomes to investigate the delivery of smoking cessation interventions and any evidence for the potential effectiveness of these interventions in terms of quit attempts and changes of smoking status. Specifically, we looked at whether or not patients had entries in their electronic health records for

1. advice to quit smoking,

2. referrals to stop-smoking services,

3. prescriptions for smoking cessation medication (NRT, varenicline or bupropion),

4. recorded quit attempts,

5. changes of smoking status to ex-smoker or non-smoker within 6 months from the index event, that is, the date (or the randomly selected one in case of multiple dates) when the smoking status was recorded as current smoker for that individual. Prescriptions for smoking cessation medications were identified using the relevant British National Formulary codes. ${ }^{22}$ The read code lists for the other four types of outcome were created using standard methods ${ }^{23}$ and were approved by a GP. Specifically, quit attempts were identified using codes for changes of smoking status to 'ex-smoker' or 'non-smoker', clear quit attempts (eg, 'Recently stopped smoking'), referrals to stop-smoking services (excluding codes related to referrals which were merely offered or declined) and codes indicating that the patient was being prescribed drug treatment for smoking cessation.

\section{Recorded mental health status}

Smokers were grouped into three cohorts of patients depending on whether they had

1. a history of SMI, that is, a record of SMI diagnosis at any time in their healthcare record,

2. no history of SMI but recent recorded diagnoses or symptoms of depression,

3. no history of SMI nor recent recorded diagnoses or symptoms of depression.

People with a history of SMI were identified using read codes for diagnoses of bipolar disorder, schizophrenia and other non-organic psychotic illnesses (eg, delusional disorder) or indicating the inclusion on the SMI register. Individuals were considered as having had recent episodes of depression if during the year prior to the index date, or since their registration with the practice if later, they had at least one entry in their medical records for symptoms or diagnoses of depression. Read codes related to history of depression were excluded to avoid historical episodes of depression being treated as incident cases.

\section{Statistical analysis}

We calculated the proportion of people who had the outcomes of interest during the 6-month window following the index date. These proportions, along with 

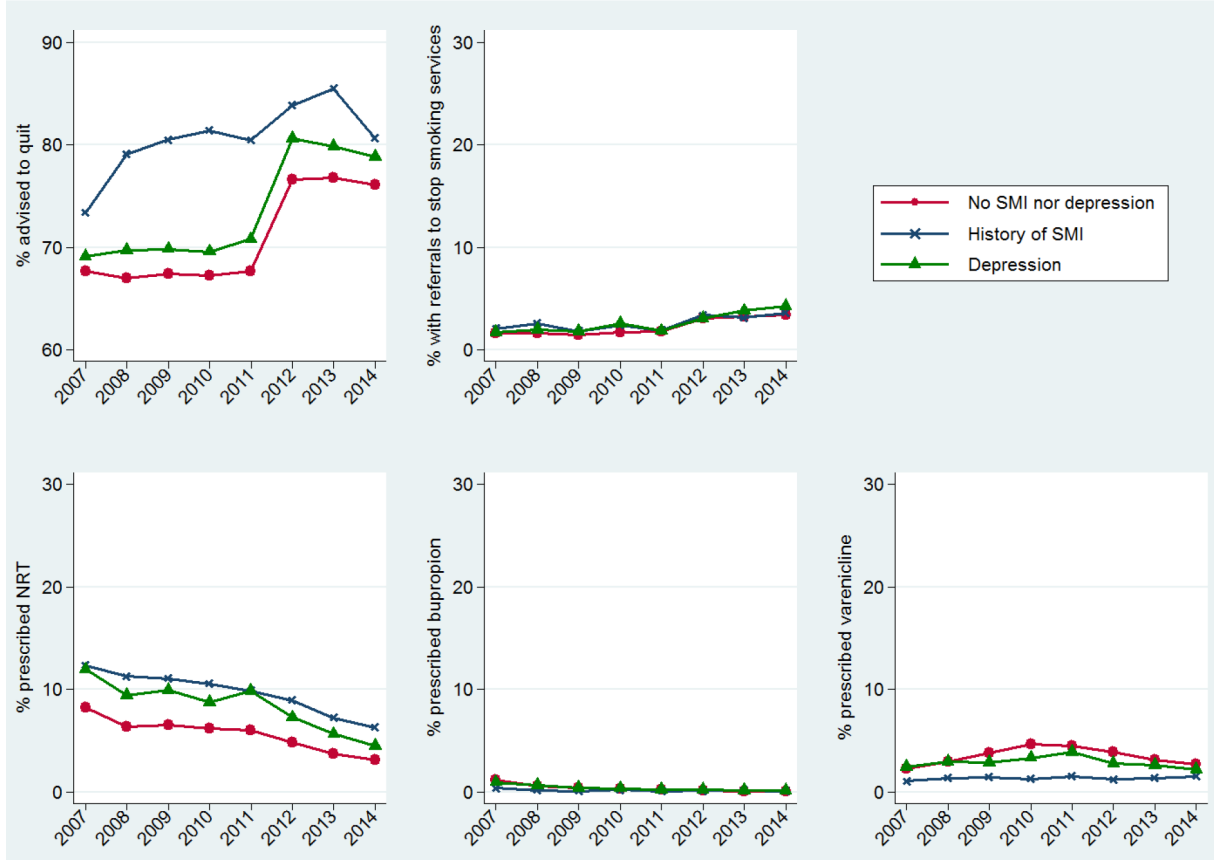

Figure 1 Annual proportions of smokers who received smoking cessation interventions within 6 months from the index smoking status update. Proportions are plotted by mental health condition and in relation to the calendar year in which the index smoking status update was recorded. SMI, severe mental illness.

95\% CIs, were stratified by mental health group and were derived in relation to the calendar year in which the index smoking status update was recorded. Since data from patients attending the same GP practice are likely to be correlated, the $95 \%$ CIs were calculated using robust standard errors ${ }^{24} 25$ to account for the data clustering.

We also used direct standardisation ${ }^{26}$ to remove differences in the age and sex distributions across the three groups of patients. Specifically, age was categorised into eight groups $(18-24,25-34,35-44, \ldots, 75-84$ and $85+)$ and the cohort of patients with no history of SMI nor depression was treated as the reference population. The standardisation was carried out separately for each calendar year.

All analyses were performed using Stata V.14. ${ }^{27}$

\section{Patient and public involvement}

People with lived experience (including LC, co-author) and a support worker from the McPin Foundation were involved from the inception of the study, including informing the idea, the design and protocol for the funder. They actively contributed throughout, attending study meetings, contributing to the interpretation of the findings and commenting on drafts of the paper. This included highlighting ongoing misconceptions around the safety of varenicline/bupropion in people with mental health problems and the importance of the quality of advice given for smoking cessation in the context of ongoing mental health symptoms.

\section{RESULTS}

Between 1 January 2007 and 31 December 2014, there were 882849 patients who met the inclusion criteria and had at least one smoking status update to current smoker. Table 1 reports descriptive statistics for these patients, stratified by mental health condition. Smokers with a history of SMI tended to be older than other smokers.

\section{Smoking cessation interventions}

The proportions of patients who were advised to quit, received referrals to stop-smoking services or were prescribed cessation medication within 6 months from the index date are displayed in figure 1 by calendar year and mental health group. The corresponding numeric values and 95\% CIs are reported in table 2. Age and gender standardisation of these proportions did not lead to significantly different findings so, for simplicity, only the unstandardised results are reported hereafter.

\section{Advice to quit smoking}

The majority $(>70 \%)$ of the smokers who entered our study received advice to quit within 6 months from the index smoking status update, with the proportion reaching $80 \%$ among those with a history of SMI. When we looked at trends over time we observed similar patterns in the annual percentages of smokers advised to quit among those with depression and those with no mental health problems, with a steep increase between 2011 and 2012 . The corresponding percentages for people with SMI were consistently higher than in the other two cohorts of patients across the whole study period but differences greatly reduced after 2012 . 
Table 2 Annual proportions (and 95\% Cls) of smokers who received smoking cessation interventions within 6 months from the index date

\begin{tabular}{|c|c|c|c|c|c|}
\hline & \multirow{2}{*}{$\begin{array}{l}\text { Advice to quit smoking } \\
\%(95 \% \mathrm{Cl})\end{array}$} & \multirow{2}{*}{$\begin{array}{l}\text { Referrals to smoking } \\
\text { cessation services }\end{array}$} & \multicolumn{3}{|c|}{ Smoking cessation drug therapy } \\
\hline & & & $\begin{array}{l}\text { NRT } \\
\%(95 \% \mathrm{Cl})\end{array}$ & $\begin{array}{l}\text { Bupropion } \\
\% \text { (95\% Cl) }\end{array}$ & $\begin{array}{l}\text { Varenicline } \\
\%(95 \% \mathrm{Cl})\end{array}$ \\
\hline \multicolumn{6}{|c|}{ History of SMI } \\
\hline 2007 & 73.39 (70.88 to 75.77$)$ & 2.09 (1.50 to 2.88$)$ & 12.34 (11.05 to 13.76$)$ & 0.38 (0.20 to 0.71$)$ & 1.04 (0.65 to 1.66$)$ \\
\hline 2008 & 79.07 (76.79 to 81.18$)$ & 2.57 (1.50 to 4.37$)$ & 11.26 (9.78 to 12.92$)$ & 0.16 (0.05 to 0.51$)$ & 1.37 (0.91 to 2.04$)$ \\
\hline 2010 & 81.37 (78.89 to 83.62$)$ & 2.39 (1.64 to 3.48$)$ & 10.54 (9.06 to 12.24 ) & 0.19 (0.06 to 0.60$)$ & 1.29 (0.76 to 2.18$)$ \\
\hline 2011 & 80.43 (77.81 to 82.81$)$ & 1.88 (1.24 to 2.82$)$ & 9.85 (8.31 to 11.64$)$ & 0.07 (0.01 to 0.48$)$ & 1.54 (1.05 to 2.27$)$ \\
\hline 2012 & 83.83 (81.57 to 85.85$)$ & 3.37 (2.31 to 4.89$)$ & 8.95 (7.42 to 10.75$)$ & 0.14 (0.03 to 0.54$)$ & $1.24(0.79$ to 1.95$)$ \\
\hline 2013 & 85.47 (83.27 to 87.42$)$ & 3.12 (2.13 to 4.54$)$ & 7.23 (5.98 to 8.71$)$ & 0.14 (0.04 to 0.56$)$ & 1.35 (0.85 to 2.12$)$ \\
\hline 2014 & 80.60 (77.61 to 83.28$)$ & 3.62 (2.41 to 5.40$)$ & 6.29 (4.95 to 7.96$)$ & 0.09 (0.01 to 0.61$)$ & 1.55 (1.00 to 2.40$)$ \\
\hline 2009 & 69.83 (68.02 to 71.58$)$ & 1.81 (1.43 to 2.30$)$ & $9.96(9.12$ to 10.86$)$ & 0.38 (0.26 to 0.55$)$ & 2.87 (2.44 to 3.36$)$ \\
\hline 2010 & 69.58 (67.68 to 71.42$)$ & 2.58 (1.97 to 3.37$)$ & 8.74 (7.84 to 9.73$)$ & $0.36(0.23$ to 0.56$)$ & 3.34 (2.91 to 3.82$)$ \\
\hline 2011 & 70.78 (68.93 to 72.57$)$ & 1.85 (1.32 to 2.60$)$ & 9.83 (8.87 to 10.87$)$ & 0.25 (0.15 to 0.41$)$ & 3.88 (3.35 to 4.48$)$ \\
\hline 2012 & 80.60 (79.09 to 82.02$)$ & 3.09 (2.34 to 4.06$)$ & 7.27 (6.55 to 8.07 ) & 0.24 (0.15 to 0.39$)$ & 2.80 (2.42 to 3.24$)$ \\
\hline 2013 & 79.83 (78.26 to 81.32$)$ & 3.80 (2.95 to 4.87 ) & 5.65 (4.96 to 6.42 ) & 0.16 (0.09 to 0.28$)$ & 2.65 (2.23 to 3.15$)$ \\
\hline 2014 & 78.81 (76.79 to 80.70$)$ & 4.28 (3.19 to 5.72$)$ & 4.51 (3.79 to 5.36 ) & 0.13 (0.06 to 0.28$)$ & 2.21 (1.80 to 2.72$)$ \\
\hline \multicolumn{6}{|c|}{$\begin{array}{l}\text { No SMI nor } \\
\text { depression }\end{array}$} \\
\hline 2007 & 67.63 (66.10 to 69.12$)$ & 1.60 (1.31 to 1.96$)$ & 8.26 (7.81 to 8.73 ) & 1.16 (1.06 to 1.26$)$ & 2.26 (1.99 to 2.57 ) \\
\hline 2014 & 76.11 (74.5 to 77.66$)$ & 3.43 (2.62 to 4.48$)$ & 3.12 (2.82 to 3.45$)$ & 0.09 (0.07 to 0.12$)$ & 2.71 (2.48 to 2.96$)$ \\
\hline
\end{tabular}

Proportions are reported by mental health condition and in relation to the calendar year in which the index event was recorded.

NRT, nicotine replacement therapy; SMI, severe mental illness.

\section{Referrals to smoking cessation services}

The proportion of current smokers recorded as being referred to stop-smoking services was very low $(<5 \%)$. A small increase was observed over time, with the proportion for example for those with depression increasing from $1.7 \%$ in 2007 to $4.3 \%$ in 2014 , but no significant differences were found when comparing those with SMI or depression and those without.

\section{Smoking cessation pharmacotherapy}

Overall, NRT was the medication most commonly prescribed for smoking cessation within primary care. The proportion of current smokers who had prescriptions for NRT during the 6 months from when their smoking status was updated was $10.1 \%$ among the patients with a history of SMI, $8.7 \%$ among those with depression and
$5.9 \%$ among the general population without depression or SMI. In contrast, rates of varenicline or bupropion prescribing were very low, especially in the SMI group. When we examined temporal changes of pharmacotherapy prescribing, we observed a clear decline over time in the proportion of smokers who were prescribed NRT by their GP, with rates of prescribing of NRT consistently higher in those with SMI and depression than the general population without these conditions.

\section{Evidence of attempts to quit smoking}

The proportions of smokers for whom we have evidence of quit attempts or who had a change of smoking status during the 6 months following their smoking status update are displayed in figure 2 and are reported in table 3 along with the 95\% CIs. Age-standardised and sex-standardised 

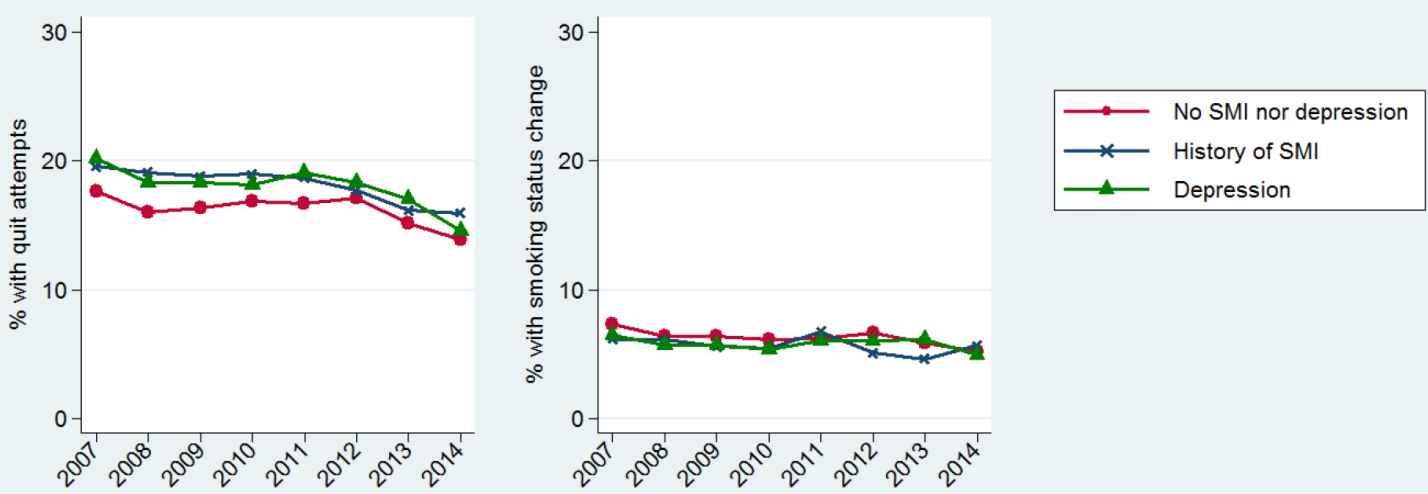

Figure 2 Annual proportions of smokers with quit attempts or changes of smoking status recorded within 6 months from the index smoking status update. Proportions are plotted by mental health condition and in relation to the calendar year in which the smoking status update was recorded. SMI, severe mental illness.

proportions were derived but they did not significantly alter our findings so, as for the smoking cessation interventions, they are here omitted.

\section{Recorded quit attempts}

Overall, smokers with recognised poor mental health were more likely than those without mental ill-health to have at least one quit attempt (defined by either codes of quit attempts or other evidence of attempted quitting, such as the prescription of smoking cessation medication) recorded during the 6 months after the index date. This was also observed across all the time points, although the gap reduced towards the end of the study period. In all three cohorts of smokers, the annual proportions of people with recorded quit attempts showed a reduction after 2012. In a supplementary analysis where we investigated the single components defining a recorded quit attempt we found that this reduction was mainly driven by the decline in NRT prescribing by GPs over this time.

\section{Changes of smoking status}

Changes of smoking status recorded within 6 months from the index smoking status update were observed in $5.7 \%$ of smokers with SMI as compared with $5.9 \%$ among those with depression and $6.4 \%$ among the other smokers. The time trends of these proportions remained fairly stable and did not show large differences across the three cohorts of smokers.

\section{DISCUSSION}

Our study shows that most GPs recorded providing smoking cessation advice to patients who are identified as current smokers, although the duration and quality of the advice provided cannot be determined from our data. Rates of recorded smoking cessation advice in UK primary care were high for all three groups of patients and highest in those with SMI. However, increases in smoking cessation advice over time were not accompanied by increases in the prescription of smoking cessation medication, recorded quit attempts or changes in smoking status. Few people $(<5 \%)$ were recorded as being referred to smoking cessation services, with a small upward trend over time, but no significant differences were observed between those with and without mental health conditions. NRT prescribing by GPs was higher in smokers with SMI and depression, although it declined over time in all groups. Varenicline and bupropion prescribing was very low, and less common in those with SMI.

There were temporal trends in recorded smoking cessation interventions in primary care. We observed a steep increase in recorded advice between 2011 and 2012, particularly for those without SMI (including those with depression). The percentage of smokers with SMI recorded as having received smoking cessation advice was consistently higher than in the other two cohorts of patients across the whole study period but differences observed greatly reduced after 2012. Studies in the USA have similarly found higher rates of smoking cessation advice given to smokers with SMI. ${ }^{28}$ The increase in advice to quit smoking given to non-SMI populations post 2012 in our study may be due to changes in incentivisation of recording of smoking advice in England. Before 2012, the QOF incentives scheme rewarded GPs for providing smoking cessation advice but this was only in relation to smokers with specific medical conditions, which included those with SMI (but not depression) from 2006. In April 2012, a new incentive was introduced to encourage GPs to provide smoking cessation support and treatment to all current smokers aged 15 years or over, regardless of their medical history. This incentivisation seems to have worked to increase the recording (and one presumes delivery) of smoking cessation advice by GPs and recorded referrals to smoking cessation services. ${ }^{29}$ However, our findings demonstrated no corresponding rise in prescribing of smoking cessation medication, quit attempts or changes in smoking status over the same time period, suggesting that this rising reported cessation advice was not effective in influencing quit rates. From 
Table 3 Annual proportions (and 95\% Cls) of smokers with quit attempts or a change of smoking status recorded within 6 months from the index smoking status update

\begin{tabular}{|c|c|c|}
\hline & $\begin{array}{l}\text { Recorded quit } \\
\text { attempts }\end{array}$ & $\begin{array}{l}\text { Change of smokin } \\
\text { status }\end{array}$ \\
\hline \multicolumn{3}{|c|}{$\begin{array}{l}\text { History of } \\
\text { SMI }\end{array}$} \\
\hline 2007 & 19.56 (17.98 to 21.24$)$ & $6.13(5.13$ to 7.31$)$ \\
\hline 2008 & 19.07 (17.05 to 21.27$)$ & 6.12 (4.98 to 7.50$)$ \\
\hline 2009 & 18.79 (16.82 to 20.94$)$ & 5.59 (4.68 to 6.67 ) \\
\hline 2010 & 18.95 (16.90 to 21.19$)$ & 5.43 (4.36 to 6.75$)$ \\
\hline 2011 & 18.63 (16.62 to 20.83$)$ & 6.77 (5.63 to 8.12 ) \\
\hline 2012 & 17.69 (15.55 to 20.05$)$ & 5.09 (4.09 to 6.33 ) \\
\hline 2013 & $16.16(14.05$ to 18.52$)$ & 4.61 (3.61 to 5.86 ) \\
\hline 2014 & 15.95 (13.69 to 18.50$)$ & 5.69 (4.47 to 7.22$)$ \\
\hline \multicolumn{3}{|c|}{ Depression } \\
\hline 2007 & 20.20 (19.13 to 21.31$)$ & $6.46(5.87$ to 7.11$)$ \\
\hline 2008 & 18.32 (17.09 to 19.61$)$ & 5.73 (5.21 to 6.30$)$ \\
\hline 2009 & $18.29(17.17$ to 19.47$)$ & $5.70(5.10$ to 6.38$)$ \\
\hline 2010 & 18.15 (16.95 to 19.42$)$ & 5.38 (4.84 to 5.96$)$ \\
\hline 2011 & 19.09 (17.90 to 20.34$)$ & 6.01 (5.43 to 6.65$)$ \\
\hline 2012 & 18.29 (17.09 to 19.55$)$ & 6.02 (5.46 to 6.63$)$ \\
\hline 2013 & $17.02(15.73$ to 18.40$)$ & 6.15 (5.61 to 6.75$)$ \\
\hline 2014 & 14.59 (13.18 to 16.12$)$ & 4.92 (4.31 to 5.61$)$ \\
\hline \multicolumn{3}{|c|}{$\begin{array}{l}\text { No SMI nor } \\
\text { depression }\end{array}$} \\
\hline 2007 & 17.64 (16.97 to 18.34$)$ & 7.31 (7.01 to 7.63$)$ \\
\hline 2008 & $15.97(15.20$ to 16.77$)$ & 6.36 (6.06 to 6.66$)$ \\
\hline 2009 & 16.36 (15.66 to 17.08$)$ & 6.36 (6.07 to 6.65$)$ \\
\hline 2010 & 16.82 (16.11 to 17.56$)$ & 6.15 (5.85 to 6.46$)$ \\
\hline 2011 & 16.68 (16.00 to 17.37$)$ & 6.22 (5.91 to 6.55$)$ \\
\hline 2012 & $17.14(16.26$ to 18.06$)$ & 6.62 (6.34 to 6.92$)$ \\
\hline 2013 & $15.19(14.32$ to 16.10$)$ & 5.91 (5.64 to 6.20$)$ \\
\hline 2014 & $13.84(12.84$ to 14.90$)$ & 5.22 (4.95 to 5.50$)$ \\
\hline
\end{tabular}

Proportions are reported by mental health condition and are derived in relation to the calendar year in which the index date falls.

SMI, severe mental illness.

our data we cannot determine the quality of advice given, but it is likely to be brief when opportunistic, and qualitative research has found that it can be confrontational in approach. ${ }^{30}$ Previous research has also shown that primary care physicians are more likely to 'Ask' (ask all patients about tobacco use) and 'Advise' (advise all tobacco users to quit) than they are to 'Assess' (assess the willingness to quit), 'Assist' (assist with quitting) or 'Arrange' (arrange follow-up) as part of the 5A's strategy to support smoking cessation. ${ }^{31}$ Our findings support that these latter stepsassessing motivation to quit, providing assistance and follow-up-may be key missing steps in supporting people with mental health conditions to quit. ${ }^{32}$

The number of recorded quit attempts in our study had, if anything, a downward trend. However, this appeared to be explained by reducing rates of NRT prescribing by GPs, which in turn may be driven by a corresponding rise in NRT uptake outside of primary care and increasing popularity of e-cigarettes. Our data source does not contain information on over-the-counter medication. Previous research has shown that the use of e-cigarettes in smokers increased between 2011 and 2013 and then levelled off afterwards. ${ }^{33}$ Beard $e t$ al reported that, after adjusting for confounding, the use of e-cigarettes for quitting was negatively associated with NRT on prescription. ${ }^{34}$ We found that NRT prescribing was higher in those with depression and SMI than the general population without these conditions, which could be explained by corresponding lower prescribing of bupropion or varenicline (in those with SMI) or by higher attendance rates at GPs in these groups (increasing accessibility to NRT via GPs) or higher levels of unemployment and associated free prescriptions for NRT which they may otherwise need to purchase.

In all three groups in our study, the proportion of people who changed their recorded smoking status from current smoker to ex-smoker was lower in 2014 than in 2007 suggesting that, while other evidence indicates uptake of smoking is going down (proportions of never smokers are increasing over time in England ${ }^{35}$ thus reducing overall smoking prevalence, in those that do smoke slightly fewer are quitting than in previous years. We found no major differences in changes of recorded smoking status from current to ex-smoker (indicating a successful quit attempt) in those with mental health conditions compared with the general population, which is in contrast to other evidence suggesting quit rates may be lower in those with SMI. ${ }^{36}$ This might be explained by an under-recording of smoking status changes in those without mental health conditions as they visit their GP less frequently.

Rates of prescribing of varenicline and bupropion were very low overall, and even lower for those with SMI, despite good evidence of effectiveness of both drugs in those with SMI in increasing medium-long term quit rates $^{37} 38$ and some evidence that varenicline may be more effective than NRT. ${ }^{39} 40$ Low prescribing probably reflects concerns among GPs and patients regarding the side effects of these two drugs during this period. In 2007, the US Food and Drug Administration (FDA) announced investigations into the safety of varenicline following concerns related to suicidality and other neuropsychiatric adverse events. Similar concerns were subsequently raised for bupropion too, prompting the FDA to issue in 2009 a black-box warning (the FDA's most serious type of warning) for both varenicline and bupropion. Subsequent studies including large scale trials found no evidence to support these concerns ${ }^{364142}$; however, the FDA warning for possible serious neuropsychiatric adverse events in patients quitting smoking was not 
removed until December 2016. Information campaigns may be needed for both smokers with mental health conditions and primary care providers to address this and encourage a greater uptake of prescribing of these drugs in people with mental health problems.

To our knowledge, this is the first study to explore time trends across a range of primary care management strategies for smoking cessation in people with mental health conditions using a large nationally representative dataset. As a study of routinely collected primary care data there are some inherent limitations, the key one being that we were only able to include pharmacotherapy prescribed by GPs and had no information on over-the-counter treatments, including the rising use of e-cigarettes. There is evidence however that recorded prescriptions for smoking cessation medication are comparable to national dispensing data and are a valid source for monitoring trends in prescribing for smoking cessation. ${ }^{43} \mathrm{We}$ are only able to report on recorded data, and some interventions (eg, advice) may occur but are not entered into the patient's record. However, information on prescription is of high quality in THIN and recorded advice levels were very high, suggesting that this was not a significant problem, though changes in recording practices over time may explain some of the patterns we observed. The prescribing records in our data source represent prescriptions issued by GP practices, and patients may not go on to take these medications. We included the issue of smoking cessation medication as an indicator of a 'quit attempt' (an intention to try to quit) and this may overestimate true quit attempts as not all patients will actually carry on to try stopping smoking. It is quite likely, nonetheless, that quit attempts were under-recorded as many people will not report this to their GP. Changes to smoking status will also depend on the GP becoming aware of this during the follow-up period, meaning that these may also be underrecorded. As those with mental health conditions visit their GP more often, there are more opportunities for them to receive smoking cessation support in this setting and it is possible that this explains the slightly higher recorded NRT prescribing observed in this group. This is not necessarily an indicator of better quality smoking cessation support in these populations.

Our results show that while smoking cessation advice is both very high and recorded as being offered more frequently in those with SMI this gap has narrowed in more recent years (probably due to changes in how recording of smoking cessation advice is incentivised), and changes in levels of advice is not linked to corresponding changes in quit attempts or smoking status. This is of concern given the ongoing high smoking rates in those with poor mental health, particularly those with SMI. ${ }^{44}$ There is some evidence that better quit rates can be achieved when smoking cessation is integrated within specialist mental healthcare settings ${ }^{45}$ or with the addition of spirometry and feedback on lung age and degree of airways obstruction. ${ }^{46}$ Our findings suggest that in order to close the widening gap in smoking prevalence and its consequences for people with mental health conditions, the focus in primary care should change from the quantity of advice given to the quality. This should include routine assessment of willingness to change, greater provision of assistance to quit and arranging follow-up as part of a '5As' strategy ${ }^{31}$ and could include other elements such as spirometry with feedback to better support smoking cessation in people with mental health conditions. Incentivisation schemes for GPs should reflect this, in particular as due to funding restraints this is often the main source of smoking cessation support for people with mental health conditions.

\section{CONCLUSIONS}

Recorded smoking cessation advice delivered by GPs was very high at times when GPs reviewed an individual's smoking status, and higher in those with SMI. We found no evidence of consistent inequalities in access to smoking cessation interventions in primary care for people with recognised mental illness. In order to address the widening gap in smoking prevalence in those with poor mental health compared with those without, the emphasis should now be on addressing the quality of advice and support provided in primary care.

\section{Author affiliations}

${ }^{1}$ Guy's Cancer Centre, King's College London, London, UK

${ }^{2}$ Faculty of Brain Sciences, University College London, London, UK ${ }^{3} \mathrm{McPin}$ Foundation, London, UK

${ }^{4}$ School of Health and Related Research, The University of Sheffield, Sheffield, UK ${ }^{5}$ Department of Primary Care \& Population Health, University College London, London, UK

The pre-publication history for this article, or part of it, is not displayed. BMJ Open aims to promote transparency in the publication process by publishing reviewer reports and previous versions of manuscripts as pre-publication histories. This means that accepted papers usually have their prepublication history posted alongside them. This comprises all previous versions of the manuscript, the reviewers' comments, and the authors' responses to all the comments from reviewers and editors. For clinical trials, this also includes the study protocol. However, in a small number of cases, after careful consideration, we decide not to publish the pre-publication history, or part of it. That decision has been taken in respect of this article. We do not provide reasons in specific cases. However, examples could include cases involving stigmatized illnesses raising issues of reviewer confidentiality and dataprotection, or where there are legal or regulatory considerations. Whatever the reason, the decision has no bearing at all on the quality or integrity of the prepublication process. In all cases where we have determined that the prepublication record, or part of it,should not be publicly available, we expect that authors will respect this decision and likewise refrain from sharing it.

\section{Twitter David 0sborn @oosborn_ucl}

Acknowledgements We would like to thank Dan Robotham (McPin Foundation) who supported lived experience involvement in a complex data study. We also thank Marina Chrysou (Smokefree Project Officer, Islington Council), Dr Hannah Jordan (University of Sheffield) and Professor Yoav Ben-Shlomo (University of Bristol) for their advice throughout the project.

Contributors KRW and DO conceived the study, all authors designed the study and developed the protocol, MF extracted and analysed the data, LC provided lived experience perspectives, all authors contributed to the interpretation of the findings, MF and KRW drafted the paper, all authors made significant contributions to drafts of the paper and approved the final draft. KRW is the guarantor for the study.

Funding This paper presents independent research funded by the National Institute for Health Research (NIHR) School for Public Health Research (Grant no. 
SPHR-UCL-PH101-SCS). The views expressed are those of the authors and not necessarily those of the NHS, the NIHR or the Department of Health and Social Care. The NIHR SPHR is a partnership between the Universities of Sheffield; Bristol; Cambridge; Imperial; and University College London; The London School for Hygiene and Tropical Medicine (LSHTM); LiLaC - a collaboration between the Universities of Liverpool and Lancaster; and Fuse - The Centre for Translational Research in Public Health a collaboration between Newcastle, Durham, Northumbria, Sunderland and Teesside Universities.

\section{Competing interests None declared.}

Patient and public involvement Patients and/or the public were involved in the design, or conduct, or reporting, or dissemination plans of this research. Refer to the Methods section for further details.

Patient consent for publication Not applicable.

Ethics approval Use of THIN for scientific research was approved by the NHS South-East Multi-Centre Research Ethics Committee in 2003. Scientific approval to undertake this study was obtained from IQVIA World Publications Scientific Review Committee (SRC) in November 2017 (SRC Reference Number: 17THIN103).

Provenance and peer review Not commissioned; externally peer reviewed.

Data availability statement Data may be obtained from a third party and are not publicly available. Read code lists are available from the corresponding author at k.walters@ucl.ac.uk. No additional data available due to the nature of the dataset (healthcare records)

Open access This is an open access article distributed in accordance with the Creative Commons Attribution 4.0 Unported (CC BY 4.0) license, which permits others to copy, redistribute, remix, transform and build upon this work for any purpose, provided the original work is properly cited, a link to the licence is given, and indication of whether changes were made. See: https://creativecommons.org/ licenses/by/4.0/.

ORCID iD

Kate R Walters http://orcid.org/0000-0003-2173-2430

\section{REFERENCES}

1 Whiteford HA, Ferrari AJ, Degenhardt L, et al. The global burden of mental, neurological and substance use disorders: an analysis from the global burden of disease study 2010. PLoS One 2015;10:e0116820.

2 Laursen TM. Life expectancy among persons with schizophrenia or bipolar affective disorder. Schizophr Res 2011;131:101-4.

3 John A, McGregor J, Jones I, et al. Premature mortality among people with severe mental illness - new evidence from linked primary care data. Schizophr Res 2018;199:154-62.

4 Hayes JF, Marston L, Walters K, et al. Mortality gap for people with bipolar disorder and schizophrenia: UK-based cohort study 20002014. Br J Psychiatry 2017;211:175-81.

5 Fluharty M, Taylor AE, Grabski M, et al. The association of cigarette smoking with depression and anxiety: a systematic review. Nicotine Tob Res 2017;19:3-13.

6 Weinberger $\mathrm{AH}$, Chaiton $\mathrm{MO}, \mathrm{Zhu}$ J, et al. Trends in the prevalence of current, daily, and Nondaily cigarette smoking and quit ratios by depression status in the U.S.: 2005-2017. Am J Prev Med 2020;58:691-8.

7 Osborn DPJ, Hardoon S, Omar RZ, et al. Cardiovascular risk prediction models for people with severe mental illness: results from the prediction and management of cardiovascular risk in people with severe mental illnesses (primrose) research program. JAMA Psychiatry 2015;72:143-51.

8 Richardson S, McNeill A, Brose LS. Smoking and quitting behaviours by mental health conditions in Great Britain (1993-2014). Addict Behav 2019;90:14-19.

9 Mathew AR, Robinson JD, Norton PJ, et al. Affective trajectories before and after a quit attempt among smokers with current depressive disorders. Nicotine Tob Res 2013;15:1807-15.

10 Cavazos-Rehg PA, Breslau N, Hatsukami D, et al. Smoking cessation is associated with lower rates of mood/anxiety and alcohol use disorders. Psychol Med 2014;44:2523-35.

11 Taylor G, McNeill A, Girling A, et al. Change in mental health after smoking cessation: systematic review and meta-analysis. BMJ 2014;348:g1151.

12 Banham L, Gilbody S. Smoking cessation in severe mental illness: what works? Addiction 2010;105:1176-89.
13 Secades-Villa R, González-Roz A, García-Pérez Ángel, et al. Psychological, pharmacological, and combined smoking cessation interventions for smokers with current depression: a systematic review and meta-analysis. PLoS One 2017;12:e0188849.

14 Gilbody S, Peckham E, Bailey D, et al. Smoking cessation for people with severe mental illness (SCIMITAR+): a pragmatic randomised controlled trial. Lancet Psychiatry 2019;6:379-90.

15 Szatkowski L, McNeill A. The delivery of smoking cessation interventions to primary care patients with mental health problems. Addiction 2013;108:1487-94.

16 Cook BL, Wayne GF, Kafali EN, et al. Trends in smoking among adults with mental illness and association between mental health treatment and smoking cessation. JAMA 2014;311:172-82.

17 Szatkowski L, McNeill A. Diverging trends in smoking behaviors according to mental health status. Nicotine Tob Res 2015;17:356-60.

18 Horsfall L, Walters K, Petersen I. Identifying periods of acceptable computer usage in primary care research databases. Pharmacoepidemiol Drug Saf 2013;22:64-9.

19 Szatkowski L, Lewis S, McNeill A, et al. Can data from primary care medical records be used to monitor national smoking prevalence? $J$ Epidemiol Community Health 2012;66:791-5.

20 Roland M. Linking physicians' pay to the quality of care-a major experiment in the United kingdom. $N$ Engl $J$ Med 2004;351:1448-54.

21 Marston L, Carpenter JR, Walters KR, et al. Smoker, ex-smoker or non-smoker? the validity of routinely recorded smoking status in UK primary care: a cross-sectional study. BMJ Open 2014;4:e004958.

22 Joint Formulary Committee. British National formulary. 66 edn. London: BMJ Group and Pharmaceutical Press, 2013.

23 Davé S, Petersen I. Creating medical and drug code Lists to identify cases in primary care databases. Pharmacoepidemiol Drug Saf 2009;18:704-7.

24 Huber PJ. The behaviour of maximum likelihood estimators under non-standard conditions. In: Proceedings of the 5th Berkeley Symposium on mathematical statistics and probability. Berkeley, USA: University of California Press, 1967: 221-33.

25 Royall RM. Model robust confidence intervals using maximum likelihood estimators. International Statistical Review / Revue Internationale de Statistique 1986;54:221-6.

26 Kirkwood BR, Sterne JAC, Statistics EM. Malden. 2 edn. MA: Blackwell, 2003.

27 StataCorp. Stata statistical software: release 14. College Station, TX: StataCorp LP, 2015.

28 Kalkhoran S, Thorndike AN, Rigotti NA, et al. Cigarette smoking and quitting-related factors among US adult health center patients with serious mental illness. J Gen Intern Med 2019;34:986-91.

29 Szatkowski L, Aveyard P. Provision of smoking cessation support in UK primary care: impact of the 2012 QOF revision. Br J Gen Pract 2016;66:e10-15.

30 Coleman T, Cheater F, Murphy E. Qualitative study investigating the process of giving anti-smoking advice in general practice. Patient Educ Couns 2004;52:159-63.

31 Bartsch A-L, Härter M, Niedrich J, et al. A systematic literature review of self-reported smoking cessation counseling by primary care physicians. PLoS One 2016;11:e0168482.

32 Weinberger AH. Smoking cessation and adults with serious mental illness: the need for more research at every step of the quit process. Nicotine Tob Res 2016;18:227-8.

33 Beard E, West R, Michie S, et al. Association of prevalence of electronic cigarette use with smoking cessation and cigarette consumption in England: a time-series analysis between 2006 and 2017. Addiction 2020;115:961-74.

34 Beard E, West R, Michie S, et al. Association between electronic cigarette use and changes in quit attempts, success of quit attempts, use of smoking cessation pharmacotherapy, and use of stop smoking services in England: time series analysis of population trends. BMJ 2016;354:i4645.

35 NHS Digital. Health Survey for England 2019: adults' health-related behaviours, 2020. Available: https://files.digital.nhs.uk/D4/93337C/ HSE19-Adult-health-behaviours-rep.pdf; [Accessed 29 Jun 2021].

36 Anthenelli RM, Benowitz NL, West R, et al. Neuropsychiatric safety and efficacy of varenicline, bupropion, and nicotine patch in smokers with and without psychiatric disorders (eagles): a double-blind, randomised, placebo-controlled clinical trial. Lancet 2016;387:2507-20.

37 Garcia-Portilla MP, Garcia-Alvarez L, Sarramea F, et al. It is feasible and effective to help patients with severe mental disorders to quit smoking: an ecological pragmatic clinical trial with transdermal nicotine patches and varenicline. Schizophr Res 2016;176:272-80. 
38 Peckham E, Brabyn S, Cook L, et al. Smoking cessation in severe mental ill health: what works? an updated systematic review and meta-analysis. BMC Psychiatry 2017;17:252.

39 Taylor GMJ, Itani T, Thomas KH, et al. Prescribing prevalence, effectiveness, and mental health safety of smoking cessation medicines in patients with mental disorders. Nicotine Tob Res 2020;22:48-57.

40 Davies NM, Taylor AE, Taylor GM, et al. Varenicline versus nicotine replacement therapy for long-term smoking cessation: an observational study using the clinical practice research Datalink. Health Technol Assess 2020;24:1-46.

41 Hughes JR, Stead LF, Hartmann-Boyce J, et al. Antidepressants for smoking cessation. Cochrane Database Syst Rev 2014:CD000031.

42 Thomas KH, Martin RM, Knipe DW, et al. Risk of neuropsychiatric adverse events associated with varenicline: systematic review and meta-analysis. BMJ 2015;350:h1109.
43 Langley TE, Szatkowski L, Gibson J, et al. Validation of the health improvement network (thin) primary care database for monitoring prescriptions for smoking cessation medications. Pharmacoepidemiol Drug Saf 2010;19:586-90.

44 Osborn D, Burton A, Hunter R, et al. Clinical and cost-effectiveness of an intervention for reducing cholesterol and cardiovascular risk for people with severe mental illness in English primary care: a cluster randomised controlled trial. Lancet Psychiatry 2018;5:145-54.

45 McFall M, Saxon AJ, Malte CA, et al. Integrating tobacco cessation into mental health care for posttraumatic stress disorder: a randomized controlled trial. JAMA 2010;304:2485-93.

46 Jaen-Moreno MJ, Feu N, Del Pozo Gl, et al. Chronic obstructive pulmonary disease in severe mental illness: a timely diagnosis to advance the process of quitting smoking. Eur Psychiatry 2021;64:e22. 
Correction: Time trends in access to smoking cessation support for people with depression or severe mental illness: $a$ cohort study in English primary care

Falcaro M, Osborn D, Hayes J, et al. Time trends in access to smoking cessation support for people with depression or severe mental illness: a cohort study in English primary care. BMJ Open 2021;11:e048341. doi: 10.1136/bmjopen-2020-048341

The authors want to alert the readers about the below changes:

One author was removed from the paper at their request, and the patient and public involvement box and the contributors section have been edited to reflect this. The version displayed will be the latest version.

Open access This is an open access article distributed in accordance with the Creative Commons Attribution 4.0 Unported (CC BY 4.0) license, which permits others to copy, redistribute, remix, transform and build upon this work for any purpose, provided the original work is properly cited, a link to the licence is given, and indication of whether changes were made. See: https://creativecommons.org/licenses/by/4.0/.

(c) Author(s) (or their employer(s)) 2023. Re-use permitted under CC BY. Published by BMJ.

BMJ Open 2023;13:e048341corr1. doi:10.1136/bmjopen-2020-048341corr1

Check for updates 